\title{
The 11th International Workshop on Modeling the Ocean (IWMO 2019) in Wuxi, China, on June 17-20, 2019
}

\author{
Tal Ezer ${ }^{1} \cdot$ Fanghua $\mathrm{Xu}^{2} \cdot$ Zhiyu Liu $^{3} \cdot$ Emil Stanev $^{4} \cdot$ Shanlin Wang ${ }^{3} \cdot$ Jun Wei $^{5}$ \\ Published online: 27 February 2021 \\ (C) Springer-Verlag GmbH, DE part of Springer Nature 2021
}

The 11th International Workshop on Modeling the Ocean (IWMO 2019) was hosted by Tsinghua University, National Supercomputing Center in Wuxi, China, on June 17-20, 2019. Wuxi is situated northwest of Shanghai, between the Yangtze River delta and Lake Tai, which is the third largest freshwater lake in China and a popular tourist attraction. The historical and cultural city, which traced its origin habitants to before $1000 \mathrm{BC}$, is today a city of about 5 million people and a center for industry, manufacturing, and scientific research.

The IWMO meetings were held annually for 10 years since the first IWMO meeting in Taipei in 2009, resulting in 160 research papers and editorials published in Ocean Dynamics over this period. However, this continual tradition of bringing together scientists from many different countries around the world was unexpectedly halted due to the global COVID-19 pandemic and travel restrictions, postponing the IWMO 2020 and IWMO 2021 meetings. Nevertheless, we hope to renew the IWMO tradition in 2022 and the following years to come. Completing the IWMO 2019 topical issue during the height of the pandemic was challenging, as research efforts at many labs

Responsible Editor: Jörg-Olaf Wolff

Tal Ezer

tezer@odu.edu

1 Center for Coastal Physical Oceanography, Old Dominion University, Norfolk, VA, USA

2 Department of Earth System Science, Tsinghua University, Beijing, People's Republic of China

3 State Key Laboratory of Marine Environmental Science, Xiamen University, Xiamen, People's Republic of China

4 Institute for Coastal Research, Helmholtz-Zentrum, Geesthacht, Germany

5 Department of Atmospheric and Oceanic Sciences, Peking University, Beijing, People's Republic of China slowed down and many authors and reviewers working from home. Therefore, we would like to give special thanks to all the scientists, reviewers, and editors who helped to bring this collection for fruition despite the difficult circumstances of the pandemic.

About 130 scientists from more than a dozen different countries attended the IWMO 2019 meeting, which included over 75 oral presentations and 50 poster presentations. Sessions covered various topics such as ocean circulation and dynamics, data assimilation and forecast systems, climate change, coastal modeling, air-sea interactions, and coupled biological-physical models. Continuing with the IWMO tradition of encouraging the participation of young scientists, about 20 students and postdocs presented their research and competed for the Outstanding Young Scientist Award (OYSA).

This topical collection of papers in Ocean Dynamics includes 17 peer-reviewed papers from participants of IWMO 2019. The papers went through rigorous reviews with the help of reviewers from both IWMO members and external experts. The papers in this collection were divided into several topical groups:

\section{Two papers focused on data assimilation and ocean forecast systems}

Miyazawa et al. (2020) applied and tested adjoint-free 4dVar assimilation method to improve real-time operational ocean forecast systems and overcome spatial and temporal gaps in satellite altimeter data, so that short-term and small-scale ocean current variability are better represented. Hindcast experiments demonstrated the improved skill of the system in reconstruction of the Kuroshio path near Japan.

Zhu et al. (2020) evaluated the effectiveness of assimilation of $\mathrm{T} / \mathrm{S}$ profiles from underwater gliders in combination with assimilation of satellite sea level data. The skill of the 
assimilation was tested over extreme warm eddy in the South China Sea (SCS). They found that assimilation of the two data sources together improved the skill. Sensitivity experiments with different sampling intervals of the glider data showed best results with a 12-hour sampling interval. The results can lead to improved real-time forecast systems for the SCS.

\section{Three papers addressed sea-ice modeling}

Bai et al. (2020) evaluated a coupled wave-ice model using the Finite-Volume Community Ocean Model (FVCOM) configured for the 5 Great Lakes. The model results were compared with observations of waves from buoys and from bottom-moored acoustic wave and current profiler (AWAC), as well as ice concentration data from satellites. The simulations showed how under heavy ice conditions lake ice can diminish waves in the Great Lakes, demonstrating the importance of wave-ice interactions for accurate ice modeling.

Liu et al. (2020) tested parameterization schemes of ice fragmentation in a sea-ice model of the Southern Ocean. They tested different prognostic floe size distribution schemes for ocean waves and found that the sea-ice fragmentation scheme has important impact on the mass transfer. The breakup of ice floe can affect lateral melt rates and ice thickness, so the study can help to improve sea-ice modeling.

Xiao et al. (2020) analyzed global high-resolution simulations with the Finite Element Sea Ice-Ocean Model (FESOM), focusing on sea level and ice variability in the Arctic Ocean. They showed how low-frequency modes are linked with variations in freshwater content through the Arctic oscillation (AO) and the Arctic dipole anomaly (DA). They found that recent sea ice decline contributed to spatial variations in sea level rise. The results can help to improve the prediction of regional sea level in the Arctic Ocean.

\section{Four papers focused on tides, river flows, and coastal sea level}

Bonaduce et al. (2020) used a coupled high-resolution waveocean and ocean circulation model for the Northeast Atlantic, the North Sea, and Baltic Sea to study the contribution of waves to sea level variability. The results show that inclusion of wave processes improved the representation of highfrequency sea level variability over continental shelves and modulated the surge near shelf breaks.

Ezer (2020) analyzed observations of tide gauges, surface temperatures, wind, and the Gulf Stream flow to examine potential drivers of the seasonal flooding along the U.S. East Coast. The seasonal flooding pattern was found to be affected by the annual and semiannual tidal cycles, changes in the Gulf Stream flow, and the seasonal pattern of tropical storms along the southeastern U.S. coasts. Seasonality on northeastern coasts is also affected by the pattern of winter storms and potential climatic shifts in wind patterns over recent years.

Ji and Zhang (2020) used a 2D unstructured finite element numerical model of the Pearl River Delta to study the relation between tides, river flow, and the morphology in river deltas and channel network. They found that nonlinear tidal-fluvial interactions are important and can affect the transition morphology zone between river- and tide-dominated regions. They demonstrated how the formation of the river channel is affected by tides.

Marta-Almeida et al. (2021) used a very high-resolution nested configuration of the Regional Ocean Modeling System (ROMS) to study the dynamics of river plumes in the South Brazilian Bight and the influence of the Brazil Current (BC). Results show that the $\mathrm{BC}$ prevents the river plumes from interaction with oceanic mesoscale features, so that river plumes are mainly controlled by wind forcing. The simulations explained in details the processes affecting the dispersing of river plumes.

\section{Two papers addressed climate change and long-term ocean variability}

Zhang et al. (2020) used satellite altimeter data from 1993 to 2016 to study long-term trends in the flow and path of Gulf Stream (GS). They found a significant weakening and southward shift trends in the GS flow, which may relate to variations in the North Atlantic Oscillation (NAO) and slowdown of the Atlantic Meridional Overturning Circulation (AMOC). The climatic changes were found to be more significant east of $61^{\circ} \mathrm{W}$ and less significant in the western portion of the GS.

Zou and Kaminski (2020) used coupled wave-climate models to study how the impact of climate change on ocean waves may affect potential fatigue damage to offshore floating oil field structures in the North Sea. Past simulations were compared with future simulations until 2100 that included projected emission scenarios. The results show that the effect of human-induced climate change can be detected, so that long-term changes in wave characteristics should be considered in offshore structures design.

\section{Two papers described modeling of biological-physical interactions}

Asplin et al. (2020) used an implementation of ROMS at 800$m$ resolution for the coast of Norway (the NorKys 800 system) to study the dispersion of salmon lice. The physical-biological system was evaluated against observations and demonstrated 
its usefulness for management purposes and for understanding environmental impacts on the salmon aquaculture industry.

Wang et al. (2020) used a coupled hydrodynamic and ecosystem model (SCHISM/CoSiNE) to simulate 10 years of variability of chlorophyll and nutrient dynamics in San Francisco Bay. The results show spatial and interannual variations of chlorophyll concentrations. River outflow had strong influence on nutrient concentrations, but benthic grazing can also impact phytoplankton biomass. The study demonstrated the potential of the model to simulate water quality and help river flow management in the bay.

\section{Four papers focused on theory and observations of mesoscale and submesoscale processes}

Cao et al. (2021) analyzed 15 years of satellite data in the East China Sea (ECS) to investigate the dynamics and distribution of sea surface temperature fronts. They identified major fronts in different subregions of the ECS and found that the seasonal variations and frontogenesis in each region depend on whether wind or river flow is the dominant forcing.

Ding et al. (2020) used the FVCOM model at 1- to 20-km resolution to study currents and frontal dynamics in the southern Yellow Sea. Momentum balance analysis showed currents that are regulated by barotropic and baroclinic quasigeostrophic dynamics. Model experiments investigated the influence of tides and wind. The results showed how the westward transversal current (TC) is connecting the frontal zone with the Yellow Sea Warm Current.

Galperin et al. (2021) introduced an application of a turbulence theory (the quasi-normal scale elimination theory, QNSE) to seasonal variability of mesoscale and submesoscale processes. They showed that the kinetic energy spectra are comprised of two branches, Kolmogorov and Coriolis, and so they cannot be represented by a line with a single slope. The submesoscale variability can be quantified in terms of a lone parameter, the effective submesoscale dissipation (ESD). The theory was validated against ADCP data from the Atlantic and Pacific Oceans.

Zhao et al. (2020) used a version of the ROMS model to investigate the mechanism that was responsible for observed subsurface (10-20m depth) cold water anomalies found in the Taiwan Strait. The simulations suggested that this middle layer cold anomaly was created by warming above and below this layer - the dynamics involved surface and bottom Ekman transports, surface heating, and changes in the monsoonal winds.

Acknowledgments Sponsors of the meeting include National Natural Science Foundation of China, Tsinghua University, Guangdong Ocean
University, National Supercomputing Center in Wuxi, First Institute of Oceanography, MNR, China, Second Institute of Oceanography, MNR, China, Ninecosmos Technology Co., Ltd, and Beijing Presky Technology Co. Thanks are due to all the volunteer Chinese students from Tsinghua, Guangxi, and Beijing Universities who helped with the execution of the meeting in Wuxi and to all the reviewers who helped with the IWMO special issue.

\section{References}

Asplin L, Albretsen J, Johnsen IA, Sandvik AD (2020) The hydrodynamic foundation for salmon lice dispersion modeling along the Norwegian coast. Ocean Dyn 70:1151-1167. https://doi.org/10. 1007/s10236-020-01378-0

Bai P, Wang J, Chu P, Hawley N, Fujisaki-Manome A, Kessler J, Lofgren BM, Beletsky D, Anderson EJ, Li Y (2020) Modeling the ice-attenuated waves in the Great Lakes. Ocean Dyn 70:991-1003. https://doi.org/10.1007/s10236-020-01379-Z

Bonaduce A, Staneva J, Grayek S, Bidlot J-R, Breivic O (2020) Sea-state contributions to sea-level variability in the European Seas. Ocean Dyn 70:1547-1569. https://doi.org/10.1007/s10236-020-01404-1

Cao L, Tang R, Huang W, Wang Y (2021) Seasonal variability and dynamics of coastal sea surface temperature fronts in the East China Sea. Ocean Dyn 71:237-249. https://doi.org/10.1007/ s10236-020-01427-8

Ding Y, Bao X, Zhou L, Bi C, Yao Z, Ma C, Chu Q (2020) Modeling the westward transversal current in the southern Yellow Sea entrance: a case study in winter 2007. Ocean Dyn 70:803-825. https://doi.org/ $10.1007 / \mathrm{s} 10236-020-01361-9$

Ezer T (2020) Analysis of the changing patterns of seasonal flooding along the U.S. East Coast. Ocean Dyn 70:241-255. https://doi.org/ 10.1007/s10236-019-01326-7

Galperin B, Sukoriansky S, Qiu B (2021) Seasonal oceanic variability on meso- and submesoscales: turbulence perspective. Ocean Dyn 71. https://doi.org/10.1007/s10236-021-01444-1

Ji X, Zhang W (2020) Tidal impacts on downstream hydraulic geometry of a tide-influenced delta. Ocean Dyn 70:1239-1252. https://doi. org/10.1007/s10236-020-01391-3

Liu X, Liao G, Lu C (2020) Case studies on the parameterization schemes of sea ice fragmentation for ocean waves. Ocean Dyn 70:15871601. https://doi.org/10.1007/s10236-020-01415-y

Marta-Almeida M, Dalbosco A, Franco D, Ruiz Villarreal M (2021) Dynamics of river plumes in the South Brazilian Bight and South Brazil. Ocean Dyn 71:59-80. https://doi.org/10.1007/s10236-02001397-x

Miyazawa Y, Yaremchuk M, Varlamov SM, Miyama T, Aoki K (2020) Applying the adjoint-free 4dVar assimilation to modeling the Kuroshio south of Japan. Ocean Dyn 70:1129-1149. https://doi. org/10.1007/s10236-020-01372-6

Wang Z, Chai F, Dugdale R, Liu Q, Xue H, Wilkerson F, Chao Y, Zhang Y, Zhang H (2020) The interannual variabilities of chlorophyll and nutrients in San Francisco Bay: a modeling study. Ocean Dyn 70: 1169-1186. https://doi.org/10.1007/s10236-020-01386-0

Xiao K, Chen M, Wang Q, Wang X, Zhang W (2020) Low-frequency sea level variability and impact of recent sea ice decline on the sea level trend in the Arctic Ocean from a high-resolution simulation. Ocean Dyn 70:787-802. https://doi.org/10.1007/s10236-020-01373-5

Zhang W-Z, Chai F, Xue H, Oey L-Y (2020) Remote sensing linear trends of the Gulf Stream from 1993 to 2016. Ocean Dyn 70:701712. https://doi.org/10.1007/s10236-020-01356-6

Zhao Z, Lin J, Fu J, Jiang Y (2020) Cold water anomalies in the middle layer of the northern Taiwan Strait in spring- a numerical approach. Ocean Dyn 70:1571-1585. https://doi.org/10.1007/s10236-02001412-1 
Zhu Y, Li Y, Peng S (2020) On evaluating the effect of assimilating glider-observed $\mathrm{T} / \mathrm{S}$ profiles with different horizontal resolutions and assimilation frequencies. Ocean Dyn 70:827-837. https://doi. org/10.1007/s10236-020-01366-4
Zou T, Kaminski ML (2020) Projection and detection of climate change impact on fatigue damage of offshore floating structures operating in three offshore oil fields of the North Sea. Ocean Dyn 70:1339-1354. https://doi.org/10.1007/s10236-020-01396-y 